Journal of Applied Pharmaceutical Science Vol. 6 (10), pp. 222-225, October, 2016

Available online at http://www.japsonline.com

DOI: $10.7324 / J A P S .2016 .601031$

ISSN 2231-3354 (cc)) BY-NC-SA

\title{
Clonazepam associated hypothyroidism: Aforethought on a concealed dilemma
}

\author{
Rupam Gill, Dipanjan Bhattacharjee, Navin A. Patil, Shripathy M. Bhat \\ Department of Psychiatry, Kasturba Medical College, Manipal Campus, Manipal University, Karnataka - 576104, India.
}

\begin{tabular}{l} 
ARTICLE INFO \\
\hline Article history: \\
Received on: 18/04/2016 \\
Revised on: 09/06/2016 \\
Accepted on: 19/07/2016 \\
Available online: 29/10/2016 \\
\hline Key words: \\
Benzodiazepine, Thyroid \\
stimulating hormone (TSH), \\
Naranjo's algorithm, \\
Triiodothyronine ( $\left.\mathrm{T}_{3}\right)$, \\
Clonazepam.
\end{tabular}

\begin{abstract}
Subclinical hypothyroidism or mild thyroid failure is a familiar problem, with a prevalence of $3-15 \%$ in a population without any known overt thyroid disorder. The prevalence increases with age and is relatively higher among females. Subclinical hypothyroidism is defined as serum thyroid stimulating hormone (TSH) levels above the upper limit of normal ( $4 \mathrm{mU} / \mathrm{L})$ while the triiodothyronine $\left(\mathrm{T}_{3}\right)$ and thyroxine $\left(\mathrm{T}_{4}\right)$ enduring within the normal range. Additionally, there exists a log-linear relationship between TSH and circulating $\mathrm{T}_{3}$ and $\mathrm{T}_{4}$; hence, measurement of serum TSH becomes mandatory for diagnosing mild thyroid failure when free $\mathrm{T}_{3}$ and $\mathrm{T}_{4}$ are lying within normal limits. Though, autoimmune thyroid disease is the most common cause for elevated TSH; thyroid functions can be afflicted by long-term consumption of drugs like lithium, amiodarone. The causal relationship between benzodiazepine class of drugs, particularly clonazepam and subclinical hypothyroidism has never been established clinically, yet there are some pre-clinical studies to claim the effect of benzodiazepine on thyroid functions; operating at various levels - hypothalamus, thyroid gland, peripheral cells and nuclear receptors. Henceforth, we would like to report a rare occurrence of subclinical hypothyroidism in an elderly female receiving clonazepam for her underlying psychiatric illness.
\end{abstract}

\section{INTRODUCTION}

Subclinical hypothyroidism is the most commonly prevailing thyroid disorder, seen among the adults with a prevalence range varying from $3-15 \%$ in various populations (Ayala et al., 2000). As per the European Thyroid Association (ETA) 2013 guidelines, it can be classified into two types- mild form [Thyroid Stimulating Hormone (TSH) levels as 4.0$10.0 \mathrm{mU} / \mathrm{L}$ ] and severe form [TSH levels $>10.0 \mathrm{mU} / \mathrm{L}$ ] (Pearce $e t$ al., 2013), with circulating thyroxine $\left(\mathrm{T}_{4}\right)$ and tri-iodothyronine $\left(\mathrm{T}_{3}\right)$ within the population reference range. The fallouts of subclinical hypothyroidism are manifold, with a special proclivity towards development of metabolic disorders. Further,

\footnotetext{
* Corresponding Author

Rupam Gill, Department of Pharmacology, Kasturba Medical College, Manipal Campus, Manipal University, Karnataka - 576104, India. Email: rupamkaurgill @ gmail.com
}

the degree and the duration of the elevation of serum TSH governs these verity of its consequences. Among the multitude of causative factors, development of subclinical hypothyroid state due to a wide spectrum of drugs for instance lithium (Kleiner et al., 1999) amiodarone (Ross et al., 2005), anti-thyroid drugs like carbimazole (Haugen, 2009) and tyrosinekinase inhibitors (IllouzF et al., 2009) has been well documented. Our literature search revealed that till date thyroid dysfunction, especially subclinical hypothyroidism has never been associated with clonazepam. However, we did unearth a few isolated animal and preclinical studies that have tried to examine the effect of clonazepam on thyroid functions (Khadem-Ansari et al., 2014; Constantinou et al., 2005). Hence, on the back of the evidence emerging from these few reports that have exhibited that clonazepam could potentially produce a sub-clinical or an over thypothyroid state, we hope to be the first to bring this potentially life-altering adverse effect of clonazepam to the notice of the scientific community. 


\section{CASE REPORT}

A 50-year-old lady, with no history of prior comorbidities, had attempted an episode of intentional self-harm (ISH) in June, 2015 due to severe left shoulder pain arising from the site of clavicle fixation which was done in March, 2015. Her thyroid hormone levels prior to clavicle fixation, done in view of generalized weakness, decreased appetite and increased sleep pattern, in March 2015 were found to be within the normal limits; i.e. $\mathrm{TSH}-2.6 \mathrm{mU} / \mathrm{mL}, \mathrm{T}_{3}-1.2 \mathrm{ng} / \mathrm{mL}, \mathrm{T}_{4}-6.8 \mu \mathrm{g} / \mathrm{dL}$. Following this, patient was initiated on tablet duloxetine $20 \mathrm{mg}$ and tablet clonazepam $0.5 \mathrm{mg}$, both consumed as once daily. However, in view of the persistent left shoulder pain, the patient was followed up in August, 2015.Aftera detailed evaluation, a diagnosis of osteomyelitis with discharging sinus of left clavicle was arrived upon. The patient underwent implant removal and wound debridement in August, 2015. However, the patient returned back again to the outpatient department (OPD) on $31^{\text {st }}$ August, 2015 with the complaints of severe pain in the left shoulder. For this, she underwent sinus tract excision and wound debridement. A detailed evaluation, in view of her depression and insomnia was carried out, that displayed a picture mirroring subclinical hypothyroidism with TSH level $-8.770 \mu \mathrm{U} / \mathrm{mL}, \mathrm{T}_{3}$ level -1.33 $\mathrm{ng} / \mathrm{mL}$ (normal:0.8-2.0 ng/mL) and $\mathrm{T}_{4}$ level $-10.34 \mu \mathrm{g} / \mathrm{dL}$ (normal: $5.56-12.2 \mu \mathrm{g} / \mathrm{dL}$ ). However, the patient neither developed any symptoms of hypothyroidism, nor were any signs of active thyroid inflammation observed during systemic examination, for instance, thyroid swelling, pain during deglutition. Therefore, no treatment was suggested for her sub-clinical hypothyroid state. While at the same time, to counter her worsening depression, the dosages of clonazepam and duloxetine were increasedto $1 \mathrm{mg}$ and $40 \mathrm{mg}$ once daily respectively. In view of better mental state, the patient was discharged and requested to follow-up. As per her latest reports taken 20 days later, showed that the TSH was further elevated to $10.090 \mu \mathrm{U} / \mathrm{mL}$ and her $\mathrm{T}_{3}$ and $\mathrm{T}_{4}$ values were $1.35 \mathrm{ng} / \mathrm{mL}$ and 8.36 $\mu \mathrm{g} / \mathrm{dL}$ respectively.

\section{DISCUSSION}

Clonazepam, a benzodiazepine class of drug, was introduced into the pharmaceutical market as a therapeutic option for panic and anxiety disorders and as an anti-epileptic agent (Shorter, 2005); though it's utility has been tempered by the wide array of adverse effects. In spite of an extensive quest of the existent scientific literature, we could not uncover any clinical case report or clinical study that could correlate thyroid dysfunction with clonazepam usage. Regardless, in our opinion, the patient's thyroid dysfunction can be attributed to clonazepam usage. Let us try to elaborate on our conviction by examining the chain of events as per Naranjo's algorithm (Naranjo et al., 1981).

\section{Are there previous conclusive reports on this reaction? - Unknown (score $\rightarrow$ 0)}

As previously mentioned in our introduction, we could not find any previous clinical case reports that have drawn an association between clonazepam usage and subclinical hypothyroidism.

Did the adverse event appear after the suspected drug was administered?-Yes (score $\rightarrow+2$ )

The history of the events as mapped out below throws a light on how we arrived at this score.

- Our patient was free of any co-morbidities until she suffered from clavicle fracture in March 2015. Her previous history and laboratory values indicated her to be euthyroid.

- In view of her psychiatric predisposition in June 2015, the patient was then initiated on oral duloxetine and clonazepam. Our literature search revealed no evidence, be it clinical or pre-clinical, to indicate duloxetine as a plausible cause.

- Her concomitant medications were tablet cefepime, paracetamol, pantoprazole, zolpidem, amitriptyline, vitamin $D_{3}$ injection along with oral Vitamin $D_{3}$ supplements. None of these can be attributed to her altered thyroid hormone levels.

- Later, on a subsequent visit to the hospital in August 2015, the patient thyroid function evaluation revealed her to be suffering from subclinical hypothyroidism. Antithyroid antibodies were not evaluated in view of the patient's financial constraints.

Hence, in light of the above-mentioned sequence of events, we can safely state that there exists a very strong temporal relationship between clonazepam administration and development of subclinical hypothyroidism.

\section{Did the adverse drug reaction improve when the drug was discontinued or a specific antagonist was given? - Unknown (score $\rightarrow 0$ )}

Despite the increased TSH levels in August 2015, a conscious decision was taken not to withdraw either clonazepam or duloxetine in view of the worsening psychiatric condition. Rather, to counter her worsening depression, the dosages of both clonazepam and duloxetine had to be increased. Further, in light of the absence of any documented evidence pointing towards a possibility of clonazepam use leading to subclinical hypothyroidism, clonazepam substitution was not considered.

\section{Did the adverse drug reaction re-appear when the drug was re-administered? - Unknown (score $\rightarrow \mathbf{0}$ )}

As clonazepam had not been withdrawn, the question of re-administering it is rendered moot.

\section{Are there alternative causes that could have caused this reaction? - No (Score $\rightarrow+2)$}

Despite our patient bearing a few of the well documented risk factors (Canaris et al., 2000; Parle et al., 1991; Hollowell et 
al., 2002; Szabolcs et al., 1997) associated with hypothyroidism for instance female gender, advancing age, belonging to coastal area (greater iodine intake), the patient's euthyroid status prior to being initiated on clonazepam combined with the absence of any other inciting agents, supports our conviction that there were no other root causes of the subclinical hypothyroidism. Further, the lack of any family history of thyroid disorders rules out any genetic causes for thyroid dysfunction.

\section{Did there action appear when placebo was given? - Unknown $($ Score $\rightarrow 0$ )}

As the administration of placebo was not carried out at any point of time during her treatment, hence this question is rendered moot.

\section{Was the drug detected in any body fluid in toxic concentration? - No (Score $\rightarrow 0)$}

Therapeutic monitoring of clonazepam levels was not carried out as it does not have a narrow therapeutic margin.

\section{Was the reaction more severe when the dose was decreased or less severe when the dose was decreased? - Yes $($ Score $\rightarrow+1)$}

- The patient was initiated on tablet duloxetine $20 \mathrm{mg}$ and clonazepam 0.5mginJune 2015.

- During her subsequent follow up in August2015, the doses of clonazepam and duloxetine were hiked to $1 \mathrm{mg}$ and $40 \mathrm{mg}$ respectively in view of her aggravated state of depression. Her TSH levels in August 2015 were - 8.770 $\mu \mathrm{U} / \mathrm{mL}, \mathrm{T}_{3}-1.33 \mathrm{ng} / \mathrm{mL}$ and $\mathrm{T}_{4}$ level- $10.34 \mu \mathrm{g} / \mathrm{dL}$.

- Her latest reports inOctober2015 incurred further elevated TSH levels- $10.090 \mu \mathrm{U} / \mathrm{mL}$ while $\mathrm{T}_{3}$ and $\mathrm{T}_{4}$ were within normal range.

Hence, in view of the increase seen in TSH levels when clonazepam was simultaneously hiked, we believe that the strength of causal association of clonazepam with subclinical hypothyroidism becomes stronger.

\section{Did the patient have a similar reaction to the same or similar drugs on any previous exposure? - No $($ Score $\rightarrow 0)$}

The patient's previous records suggest that the patient had been previously free from any co-morbidities and had not consumed clonazepam at any point of time in her life.

\section{Was the adverse event confirmed by objective evidence? - Unknown (Score $\rightarrow$ 0)}

Despite the limited information available with regards to clonazepam's effect on thyroid hormones, the physician had considered the possibility of drug induced sub-clinical hypothyroidism. Thus, by utilizing the Naranjo adverse drug reaction scale, we arrive at a 'probable' (total score $\rightarrow 5$ ) causal association between clonazepam and subclinical hypothyroidism in our patient.
Besides the determination of causality using Naranjo's algorithm, we also explored the possible mechanism by which clonazepam might have caused subclinical hypothyroidism in our patient. The paucity of mechanistic studies in this regard proved to be a major limiting factor. However, we did find a few animal studies that have attempted to explore the relation between clonazepam and subclinical hypothyroidism. One animal study evaluating the effect of various psychotropic drugs concluded that the only effect of benzodiazepines on thyroid function may be a decrease in circulating hormone levels (Khadem-Ansari et al., 2014). Thus anticipating from this study, it is our theory that by causing a decrease in the thyroid hormone levels, via feedback mechanism clonazepam may potentially cause an increase in the TSH levels. This would advance to a situation, where increased $\mathrm{TSH}$ would impinge on thyroid gland to produce $\operatorname{moreT}_{3} \mathrm{andT}_{4}$; while on the other side, clonazepam will simultaneously be lowering thyroid hormones, that would counterbalance the increased $T_{3}$ and $T_{4}$, thus producing a picture resembling subclinical hypothyroidism where $\mathrm{TSH}$ is raised, although $\mathrm{T}_{3}$ and $\mathrm{T}_{4}$ are within normal range. The patient was under stressful condition due to the development of discharging sinus, for which she underwent debridement and excision of sinus tract. As we know, any kind of stress to the body results in increased cortisol levels which are under the control of $\mathrm{CRH}$ (Corticotropin-releasing hormone) (Meyerhoff et al., 1988). The animal models have demonstrated that TSH secretion is stimulated by CRH and there might be an association between $\mathrm{CRH}$ and TSH in humans also (De Groefet al., 2003). Now, it has also been recognized that benzodiazepines inhibit CRH (Heberlein et al., 2008); from this, we can conclude that the rise in the patient's TSH levels though appreciable, but was not immense.

The transport of thyroid hormones $\left(\mathrm{T}_{3}\right.$ and $\left.\mathrm{T}_{4}\right)$ into the peripheral cells is an energy-dependent process; thus any condition which can alter the cellular energy production like mitochondrial dysfunction, will result in decreased transport of $T_{3}$ and $T_{4}$ into cells, leading to cellular hypothyroidism; at the same time, standard blood tests will show normal range of thyroid hormones. It is noted that even minimal damage to mitochondrial function will result in simultaneously lowered uptake of $\mathrm{T}_{4}$ into cells while uptake of $T_{3}$ is not affected; it is also established that cellular uptake for $T_{3}$ is more than $T_{4}$ to exhibit metabolic functions, thereby this cellular hypothyroidism is not detected by blood tests for thyroid function (NAH, 2016). Benzodiazepines display mitochondrial damaging property and some drugs like diazepam, lorazepam, and alprazolam, have demonstrated to inhibit $\mathrm{T}_{3}$ uptake in certain human cells (liver, neurons) and rat cells (pituitary) (Kragie and Doyle, 1992). Therefore, in our case, the decreased availability of $T_{3}$ and $T_{4}$ to the peripheral cells via feedback mechanism resulted in increased TSH levels.

Another animal study has shown benzodiazepine effect at nuclear receptors; it was observed by the researchers in this study that benzodiazepines may decrease the nuclear $\mathrm{T}_{3}$ binding density by affecting the expression and density of nuclear $T_{3}$ receptors 
(Constantinou et al., 2005). The researchers of another study have also hypothesized that clonazepam by inducing the hepatic microsomal enzymes may induce the metabolism and degradation of the thyroid hormones (Nims et al., 1997).

In light of the meager research with respect to effect of clonazepam over thyroid function, it is not possible to pinpoint the mechanism behind the development of subclinical hypothyroidism in our patient. But, a strong temporal association, absence of any other causative agents or co-morbidities when combined with the fact that an increase in the dose of clonazepam led to the worsening of the TSH levels, suggest that clonazepam, in all probability could be the inciting factor for subclinical hypothyroidism in our patient.

\section{CONCLUSION}

To conclude, the action of clonazepam over thyroid can only be better understood if more research and studies are conducted in this regard. However, in light of the widespread use of clonazepam for its various indications, it would not be bereft of scientific merit to suggest that the physicians and the psychiatrists should closely monitor the patients being initiated on clonazepam for thyroid dysfunction, especially those who possess one or more of the risk factors for sub-clinical hypothyroidism. Further, if thyroid hormone levels are found to be deranged, a close scrutiny of the patient's treatment should be carried out in order to reveal the plausible causes of hypothyroidism and a substitution of clonazepam be considered as well.

\section{ACKNOWLEDGEMENTS}

We would like to acknowledge the contribution of Manipal University in the making of this paper.

Sources of Funding: Nil.

Conflict of Interest: Authors' declare no conflict of interest.

Informed Consent: Written informed consent was obtained.

\section{REFERENCES}

Ayala AR, Danese MD, Ladenson PW. When to treat mild hypothyroidism. Endocrinol Metab Clin N Am, 2000; 29:399-15.

Canaris G J, Manowitz N R, Mayor G, Ridgway EC. The Colorado thyroid disease prevalence study. ArchIntern Med, 2000; 160:526.

Constantinou C, Bolaris S, Valcana T, Margarity M. Diazepam affects the nuclear thyroid hormone receptor density and their expression levels in adult rat brain. Neurosci Res, 2005; 52:269-75.

De Groef B, Goris N, Arckens L, Kühn ER, Darras VM. Corticotropin-releasing hormone $(\mathrm{CRH})$-induced thyrotropin release is directly mediated through $\mathrm{CRH}$ receptor type2 on thyrotropes. Endocrinology, 2003;144 (12):5537-44.

Haugen BR. Drugs that suppress TSH or cause central hypothyroidism. Best Pract Res Clin Endocrinol Metab, 2009;23 (6):793800.
Heberlein A, Bleich S, Kornhuber J, Hillemacher T. Neuroendocrine pathways in benzodiazepine dependence: new targets for research and therapy. Hum Psychopharm Clin, 2008; 23 (3):171-81.

Hollowell JG, Staehling NW, Flanders WD, Hannon WH, Gunter EW, Spencer CA, et al. Serum TSH, T (4), and thyroid antibodies in the United States population (1988to 1994): National Health and Nutrition Examination Survey (NHANES III). J Clin Endocrinol Metab, 2002; 87: 489 .

Illouz F, Laboureau-Soares S, Dubois S, Rohmer V, Rodien P. Tyrosinekinase inhibitors and modifications of thyroid function tests:a review. European Journal of Endocrinology, 2009; 160:331-36.

Khadem-Ansari M, Ahani A, Mikaeili P, Rasmi Y. Effect of benzodiazepineson thyroglobulin, anti-thyroglobulin, antithyroidperoxidase, and thyroid stimulating hormone in rat. Med J DY Patil Univ, 2014;7:447-49.

Kleiner J, Altshuler L, Hendrick V and Hershman JM. Lithiuminduced subclinical hypothyroidism: review of the literature and guidelines for treatment.J Clin Psychiatry, 1999; 60 (4):249-55.

Kragie LA, Doyle DA. Benzodiazepines inhibit temperaturedependent L-[125I] triiodothyronine accumulation into human liver, human neuroblast, and rat pituitary cell lines. Endocrinology, 1992; 130 (3):1211-16.

Meyerhoff JL, Oleshansky MA, Mougey EH. Psychologic stress increases plasma levels of prolactin, cortisol, and POMC-derived peptides inman. Psychosom Med, 1988; 50 (3):295-03.

Naranjo CA, Busto U, Sellers EM, Sandor P, Ruiz I, Roberts EA, et al. A method for estimating the probability of adverse drug reactions. Clin Pharmacol Ther, 1981; 30 (2):239-45.

National Academy of Hypothyroidism (NAH). 2016. Available at http://www.nahypothyroidism.org/thyroid-hormone-transport

Nimes RW, Prough RA, Jones CR, Stockus DL, Dragney KH, Thomas PE et al. In vivo induction and invitro inhibition of hepatic cytochrome P450 activity by the benzodiazepine anticonvulsants clonazepam and diazepam. DrugMetabDispos,1997; 25 (6):750-56.

Parle JV, Franklyn JA, Cross KW, Jones SC, Sheppard MC. Prevalence and follow-up of abnormal thyrotropin (TSH) concentrations in the elderlyin the United Kingdom. Clin Endocrinol, 1991; 34:77.

Pearce SHS, Brabant G, Duntas LH, Monzani F, Peeters RP, Razvi $\mathrm{S}$ et al. ETA Guideline: Management of Subclinical Hypothyroidism. Eur Thyroid J, 2013; 2: 215-28.

RossI L, Marshall D, Okreglicki A, Isaacs S, Levitt NS Amiodarone-induced thyroid dysfunction. S Afr Med J, 2005; 95:180-83. Shorter E. 2005. Historical Dictionary of Psychiatry. New York, USA: Oxford University Press.

Szabolcs I, Podoba J, Feldkamp J, Dohan O, Farkas I, Sajgó M et al. Comparative screening for thyroid disorders in old age in areas of iodine deficiency, long-term iodine prophylaxis and abundant iodineintake.ClinEndocrinol,1997; 47:87.

\section{How to cite this article:}

Gill R, Bhattacharjee D, Patil NA, Bhat SM. Clonazepam associated hypothyroidism: Aforethought on a concealed dilemma. J App Pharm Sci, 2016; 6 (10): 222-225. 